\title{
The Effect of a Team's Knowledge Management Practices on Team Performance : Evidence from Sri Lankan Software Development Companies and Business Process Outsourcing Companies
}

\author{
W.B.M.D.Basnayake

\section{J A S K Jayakody}

\begin{abstract}
The present study examines the effect of a teams' knowledge management practices and team performance. Drawing on the knowledge based view which says how knowledge management practices will enable the achievement of sustainable competitive advantage, this study attempted to investigate knowledge management practices at the team level and their effect on team performance in software development companies and Business Process Outsourcing companies. A hundred teams including their team leaders and team members from selected companies in Sri Lanka responded to two questionnaires. Using the Partial Least Square - Structural Equation Modeling approach, the results of the statistical analysis revealed that knowledge management practices within teams have a significant effect on team performance. Hence, this study contributes to the knowledge based view theory.
\end{abstract}

Key Words: Knowledge Retention (KR), Knowledge Management Practices (KMP), Team Performance (TP), Knowledge Based View (KBV) Theory, Sustainable Competitive Advantage (SCA).

\section{Introduction}

According to the knowledge-Based View (KBV) of the firm, intellectual resources which are also known as knowledge resources are the main organizational assets that enable sustainable competitive advantage (Drucker, 1998; Hansen \& Oetinger, 2001; Teece, 2003; Wenger \& Snyder, 2000). The firms which are able to effectively manage these knowledge resources can expect to benefit from various outcomes such as improved customer service, reduced costs in people and infrastructure, better decision making, innovation, improved corporate agility, rapid development of new product lines, quick and efficient problem resolution, and efficient transfer of best practices (Hansen \& Oetinger, 2001; Skyrme \& Amidon, 1998). Nevertheless, there is a common agreement that knowledge management will becomes the most vital competitive advantage for organizations (Drucker, 1993; Quinn, 1992; Stewart, 1997; Toffler, 1990; Ferran-Urdaneta, 1999).

Due to the importance of Knowledge Management (KM), several researchers have examined the effect of knowledge management on the different organizational outcomes. Marques and Simon (2006) have conducted a research study with the aim of studying the importance of $\mathrm{KM}$ as a source of sustainable competitive advantages for firms and to analyze how the introduction of KM practices enables improved firm performance. Further, Gloet and
Terziovski (2004) have explored the relationship between KM and innovation through measuring the effects of knowledge management approaches and innovative performance through a preliminary study focusing on the manufacturing industry. Lubit (2001) has explored how companies can best expand their knowledge resources to create not simply a competitive advantage, but a sustainable competitive advantage. Among all these organizational outcomes that have been measured, teams and team effectiveness have become important in today's organizations, with teams becoming key constituents of organizational effectiveness over the past twenty years (Wilson et al., 2007 as cited in Woerkom\& Croon, 2009). Also, since it is almost impossible for competitors to imitate, sustainable competitive advantage comes from teams more than from individuals (Barney \& Wright, 1998).

Given the difficulty in understanding knowledge management engendered by diverse meanings and disciplinary viewpoints, researchers have attempted to provide a structure to knowledge management research (Argote, McEvily \& Reagans, 2003). Yet, only a few studies have made clear attempts to operationalize and measure knowledge management (Singh \& Gupta, 2014). Moving further, as teams have appeared as ultimate operative units, defining and measuring knowledge management at the team level has become gradually more important (Singh \& Gupta, 2014). However, most studies have operationalized knowledge management at the organization level, without considering the impact that different group members within the organization may have on knowledge management (Singh \& Gupta, 2014).

Therefore, it is apparent that when particular phenomenon is studied directly at the organizational level, significant factors at the team level may be ignored, and therefore it is important to specify the level of measurement. Consequently, it is important to incorporate the impact of the teams while studying knowledge management (Singh \& Gupta, 2014). In the light of these discussions, this study identifies the impact of a team's knowledge management practices on team performance as a direct relationship which will eventually contribute to knowledge based view.

Further to above discussion, Asian countries have been found to be engaged in research in the area of knowledge management specifically India (e.g. Singh \& Gupta, 2014). Despite that fact, though the literature on 
knowledge management has significantly grown over the past decades in Sri Lanka, minimal research has been conducted in the context of the Sri Lankan corporate sector (e.g. Atapattu \& Jayakody , 2014), and this has resulted in the current theory and understanding of the strategies and tactics for developing new knowledge management initiatives being inadequate. Simultaneously, there is a limited amount of research being conducted in the area of KM of teams (e.g. Ramesh \& Tiwana, 1999; Singh \& Gupta, 2014). According to the discussions, there is a dearth of research conducted in the Sri Lankan context to examine the relationship between a team's knowledge management practices and its team performance. Accordingly, this paper addresses the lacuna in empirical studies examining the relationship between the team's knowledge management practices and team performance.

The next section of this article reviews relevant literature on team's knowledge management practices and team performance, while the third section outlines research design, along with the hypotheses. The paper concludes with a brief discussion of the theoretical implications of the study.

\section{Review of Literature}

\section{A. A team's knowledge management practices}

Knowledge management is a process that facilitates knowledge sharing and establishes learning as an endless process within an organization. Therefore, knowledge management and learning go hand in hand in organizations (Lopez, Peon \& Ordas, 2004). Davenport, De Long and Beers (1998) define knowledge management as a process of collection, distribution, and efficient use of the knowledge resource throughout an organization. O'Dell and Grayson (1998) believe that knowledge management is a strategy which has to be developed in a firm to certify that knowledge reaches the right people at the right time, and that these people should share and use information to improve the functioning of the organization. Similarly, Bounfour (2003) as cited in Singh (2008) defines knowledge management as a "set of procedures, infrastructures, technical and managerial tools, designed toward creating, sharing and leveraging information and knowledge within and around organizations" (p.5).

With scholars of different disciplinary backgrounds adopting different attempts to understand knowledge management, this has led to the presence of a "multitude of disciplinary perspectives" on knowledge management research (Argote et al., 2003). Given the complexity in studying knowledge management formed by compound meaning and disciplinary perspectives, researchers have endeavored to provide a structure to knowledge management research (Alavi \& Leidner, 2001; Argote et al., 2003). As per their view, these attempts are based on conceptual analysis and require empirical validation. At the same time, only a few studies have made clear attempts to operationalize and measure knowledge management. However, defining and measuring knowledge management at team level has become tremendously important with teams emerging as central functioning units (Singh \& Gupta, 2014).

Singh and Gupta (2014) have identified three main dimensions of knowledge management - knowledge creation, knowledge sharing and knowledge retention. Knowledge creation focuses on the process by which "new" knowledge is created and assimilated into the functioning of the organization. Knowledge sharing concepts are concerned with the process by which existing knowledge is shared and disseminated within the organization, and finally, knowledge retention concepts focus on the process by which knowledge is retained and passed on within the organization in the form of group memory, documents or routines.

\section{B. Knowledge sharing}

Knowledge sharing is known as the process by which individuals mutually exchange their tacit and explicit knowledge which in turn function to jointly create new knowledge (De Vries, Van den Hooff\& De Ridder, 2006). This shows that people make their knowledge collective through sharing, which indicates that the relationship between individual and collective (community, group, team or organization) knowledge is a crucial aspect of knowledge sharing behavior. In order for the collective to benefit from its prospective "intellectual capital", individual members must make this knowledge available, which means that they should share their knowledge with co-workers (Hooff \& Huysman, 2009).

With the different research studies conducted, it has been found that knowledge sharing is shaped by different factors, such as the culture of the organization, the nature of the technology, and the individual's values and attitudes towards sharing (Oliver, 2008; Wulff \& Ginman, 2004; Hall, 2003). Behavior by which an individual voluntarily provides other members of the organization with access to his or her knowledge and experiences is viewed as knowledge sharing in organizations (Cyr \& Choo, 2010). Knowledge sharing covers an extensive range of behaviors that are multi-faceted (Cyr \& Choo, 2010).

\section{Knowledge creation}

As per Singh and Gupta (2014), knowledge creation refers to "activities that lead to the development of "new" knowledge that may be in the form of know-how (operational knowledge), know-what (theoretical knowledge) or a combination of the two" (p.779). The new knowledge may not essentially be a new invention or an innovation. It can be attained by mimicking from an outside source, or by developing a new idea, or a combination of both (Singh \& Gupta, 2014). The knowledge creation begins with an idea or intuition arising through or originated by individuals through their intellect, experience, observation or imagination (Crossan, Lane \& White, 1999; Nonaka, 1994) or resulting from an investigative activity (Gupta, Smith \& Shalley, 2006). Nonaka (1991, 1994) suggested that knowledge creation takes place through a process called SECI which stands for Socialization, Externalization, Combination and Internalization. Accordingly, socialization will enable sharing tacit knowledge between employees at the workplace. Externalizing knowledge can be attained by 
converting commonly held tacit knowledge into explicit knowledge.

\section{Knowledge Retention}

Knowledge retention refers to knowledge residing in an organization in various forms such as in "written documentation, structured information stored in electronic databases, codified human knowledge stored in expert systems, documented organizational procedures and processes and tacit knowledge acquired by individuals and networks of individuals" (Alavi \& Leidner 2001., cited in Singh \& Gupta, 2014, p. 781). Marsh and Stock (2006) specified that organizations may develop formal routines to identify, express and store experience and knowledge developed in previous projects and document best practices for future use by employees. Hansen, Nohria and Tierney (1999) noted two distinct knowledge retention strategies such as codification and personalization. Codification refers to activities that carefully codify knowledge and store it in databases so that it can be retrieved and used easily by anyone in the company. The commonly used methods to codify and retain knowledge for future use can be identified as knowledge repositories such as share-point, common databases and e-mail groups. Personalization refers to practices where knowledge is closely tied to employees and is shared primarily through direct person-to-person contacts. Therefore the Transactive Memory System (TMS) can be identified as a fine example of knowledge retention using a personalization strategy.

\section{E. Teams and Team Performance}

Nurturing teamwork is of top priority for many leaders. Teams are serious business in today's economy as companies realize the value of team work in creating greater employee involvement, levering human resources, fostering innovation, and shoring up the bottom. In light of the above reasons, researchers have long been interested in the study of teamwork in organizations (Nelson, 1995, as cited in AlRawi, 2008). Throughout the past decades, researchers have examined the nature of teamwork in the present day and they offer a positive point of view (Cristina, 2003).

Davenport and Grover (2001) indicated that it is imperative to develop knowledge-oriented cultures where shared and unshared knowledge exchanges among individuals are provided. However, use of teams, groups, and learning communities within the organization can be considered as one way to achieve a knowledge-oriented culture. With different definitions of teams, research by Cohen and Bailey (1997) defined a team as "a collection of individuals who are interdependent in their tasks, who share responsibility for outcomes embedded in one or more larger social systems" (p.241).Teams can be incorporated as a process of knowledge management to help obtain organizational goals and outcomes, identifying knowledge management as the organizations social system.

Team performance can be defined as the degree to which a team achieves its goal or mission (Devine \& Phillips, 2001). Team performance may be evaluated qualitatively or quantitatively according to fundamental work outcomes. Another aspect which can be considered is that team members' psychological cognition, which is known as a team member's desire to cooperate and work interactively, towards the team goal. Among these two dimensions of team performance-related aspects, the first is associated with the recognition of team members or the team leader (Stewart \&Barrick, 2000), or with other objective indicators like cost reduction and production, while the latter such as job satisfaction, team commitment, or cooperation satisfaction is based on behavioral and results-oriented criteria (Kirkman \& Rosen, 1999; Nathan et al., 1991).

\section{F. Knowledge Based View theory}

The knowledge and capabilities-based views (KBV) in strategy have largely expanded resource-based reasoning by signifying that knowledge is the resource fundamental to new value creation, heterogeneity, and competitive advantage (Barney, 1991; Grant, 1996; Kogut \& Zander, 1992). However, despite the recent explosion of research into knowledge-based arguments, various fundamental constructs and questions have yet to be clearly defined and explored (Kaplan,Schenkel,von Krogh \& Weber, 2001).The knowledge-based view speculates that core capability is a knowledge set that distinguishes one group from another and provides a competitive advantage (Leonard-Barton, 1992). The knowledge set may consist of employee knowledge or skills, technical systems, managerial systems, or norms and values.

The knowledge-based approach of a firm attempts to perceive and examine how organizations create, acquire, apply, protect, and transfer knowledge. Thus, Bierly and Chakrabarti (1996) believe that competitive advantages could be generated on the basis of the knowledge possessed by a firm and its ability to develop that knowledge. In this view of the firm as a body of knowledge (Spender, 1996), the classification of the knowledge elements becomes a core aspect of the approach. The most influential and recognized typology in the field is that which differentiates between explicit and tacit knowledge (Polanyi, 1966; Nonaka \& Takeuchi, 1995; Tsoukas, 1996; Nonaka \& Konno, 1998). Thus, explicit (articulated or codified) knowledge is knowledge that can be conveyed by way of a systematized language or code, and there is no need to link it to a very specific context for it to be meaningful. In that sense, many of the elements in a firm that contain information (internal and external statistics, product descriptions, and so on) are examples of explicit knowledge which is easy to transfer.

Transferring knowledge internally sets the foundation for innovating and improving efficiency, and thereby realizing the potential value of that knowledge (Davenport \& Prusak, 1998). Nevertheless, knowledge does not always move easily across the organization, and especially its tacit elements tend to limit its mobility. With explicit knowledge, the ease of transfer between source and recipient defines its spirit and such a transfer shows that both entities can possess that knowledge through transmission by codes or symbols (Kogut \& Zander, 1992). On the contrary, an individual's or group's tacit knowledge which is embedded within the context in which it was advanced, makes its transmission very difficult and further makes it possible only by its application in practice through a slow and costly process (Grant, 1996; Szulanski, 1996; Brown \& Duguid, 1998; Wareham \& Gerrits, 1999). 


\section{Research Design}

\section{A. Sample Selection}

This study selects software development companies and Business Process Outsourcing (BPO) companies in Sri Lanka due to the heavy use of teams and also due to these industries being considered knowledge intensive organizations (Chan, 1998).

A hundred teams from software development companies and Business Process Outsourcing (BPO) companies were selected for the study. A number of members among teams is not consistent and it varies from one team to another where a team consists of approximately 5 members with the largest team having eight members and the smallest team having two members. The study has two types of respondents, namely team members and team leaders, and the study used two questionnaires. Data on team performance (dependent variable) were collected from team leaders and for other constructs, data were collected from team members. Therefore, data was collected from 450 individuals; 350 team members and 100 team leaders.

Since the unit of analysis is the team, data collected from individual respondents for all constructs, except data for team performance, were aggregated to measure scales at team level. It was assumed that responses of team members were consistent. The average Intragroup agreement (rwg) for each of the sub-scale as well as complete scales needed to be calculated. If the cut-off point for the Inter-Correlation Coefficient is greater than 0.7 (LeBreton \& Senter, 2008), the responses of each individual can be aggregated into teams. LeBreton and Senter (2008) have stated that Inter Rater Agreement (IRA) levels of .00 to .30 are considered as lack of agreement, .31 to .50 as weak agreement, .51 to .70 as moderate agreement, .71 to .90 as strong agreement, and 91 to 1.00 as very strong agreement. Having calculated the IRA using a two way random model and an absolute agreement type it was found that aggregate measure for the Intraclass Correlation Coefficient (ICC) ranged from moderate agreement to strong agreements which facilitates the justification for aggregation of individual responses for teams. Inconsistent responses of individuals had to be removed and after removing, 344 individuals remained for the aggregation purpose. Accordingly, Intragroup agreement (rwg) on the knowledge management would mean that team members evaluated those aspects in similar manner and their views are consistent with other team members (Lewis, 2003). Subsequently, 100 teams were formed converting 344 individuals into team level.

\section{B. Variables and Measurement}

With knowledge management practices within teams being defined, Singh and Gupta (2014) have identified knowledge sharing, knowledge creation, and knowledge retention as the dimensions of a team's knowledge management practices.

Team performance being the dependent variable, a five-item scale measuring performance was drawn from Amy (1999) which has been completed by team leaders.
Scales are ranged from "1" (very inaccurate) to "7" (very accurate). Examples of items are, "This team meets or exceeds its customers' expectations" and "This team keeps getting better and better". The researcher has drawn these measures as the definition of the team performance has been drawn from the same journal article. Further, many researchers have used this scale developed by Amy in their respective studies and also it is well established and has been used across cultures. The reliability coefficient for this scale in a previous study was 0.93 .

Independent variable of this study is Team's knowledge management practices which comprises three dimensions namely knowledge creation, knowledge retention and knowledge sharing

Questionnaire was drawn from Singh and Guptha (2014) where 22 items used to measure the three dimensions which make the knowledge management practices in teams. Eight items measure the knowledge sharing dimension and example items are, "My team members willingly share knowledge" and "My team members share information on problem-solving strategies that have worked well". Nine items measure the Knowledge creation dimension and under knowledge creation, examples of items are, "My team members take initiative to develop new knowledge" and "My team members are aware of latest developments in their field". Finally, five items measure the knowledge retention dimension and the example items under knowledge retention dimension are, "My team members regularly update information on the intranet (share drive, knowledge portals)" and "Knowledge of my team processes is known to many team members". This is a multi- dimensional variable and scales of these questions range from " 1 " (strongly disagree) to " 5 " (strongly agree).

Scale validity and reliability provided by Singh and Gupta (2014) from which the existing scale is drawn was 0.936. The alpha reliabilities for knowledge creation, knowledge sharing, and knowledge retention sub-scales were acceptable at both member-level $(0.869,0.852,0.825$ respectively) and team-level (0.907, 0.872, 0.898 and 0.794, respectively) data. These results indicate that the scale is internally consistent, and suggest no deletions from the scale because the item correlations and alpha reliabilities for all three sub-scales were high.

\section{Hypotheses Development}

Knowledge creation refers to "activities that lead to the development of "new" knowledge that may be in the form of know-how (operational knowledge), know-what (theoretical knowledge) or a combination of the two" (Singh \& Gupta, 2014, p.779). The new knowledge may not essentially be a new invention or an innovation and can be acquired by imitating from an external source, or it can come about by developing a new idea, or even be a combination of imitation and development (Singh \& Gupta, 2014). The knowledge creation begins with an idea or intuition arising through or originated by individuals through their intellect, experience, observation or imagination (Crossan et al., 1999; Nonaka, 1994) or resulting from investigative activity (Gupta et al., 2006). According to Nonaka (1991, 1994) knowledge creation takes place through a process of 
Proc. of The Sixth Intl. Conf. On Advances In Economics, Social Science and Human Behaviour Study - ESSHBS 2017 Copyright (C) Institute of Research Engineers and Doctors, USA .All rights reserved.

ISBN: 978-1-63248-120-7 doi: 10.15224/ 978-1-63248-120-7-44

Socialization, Externalization, Combination and Internalization (SECI cycle).

Considering team performance as the dependent variable, the definition given by Amy (1999) for team performance can be stated as "the extent to which the team satisfies customer needs and expectations" (p.357). Team performance has been addressed in team literature as a widespread framework which includes inputs such as resources and processes such as collective effort and outcomes such as specific performance indicators. (Guzzo \& Shea, 1992; Hackman, 1992, as cited in Williams \& Castro, 2010).

Faraj and Sproull (2000) found that team members' capability in carrying knowledge to bear is a significant predecessor to team effectiveness. Kanawattanachai and Yoo (2007) also report that a virtual team's ability to apply knowledge in a given context is an important antecedent to team performance. Taken as a whole, previously conducted studies confirm that a team's ability to integrate their existing stock of knowledge and apply it within a new context is an important factor that contributes to team performance. Thus, it is hypothesized that;

H1: There is a positive relationship between knowledge creation and team performance

Transactive memory system (TMS) is a specialized division of labour designed for encoding, storage and retrieval of information in a team (Huang, 2009). As per Hollingshead (2001) and Wegner (1995), it is further known as a collective memory system for communicating knowledge in the group. TMSs tend to develop over time when group members communicate, observe each other's actions and come to rely on one another to be responsible for different but complementary areas of expertise. TMSs facilitate members to learn, both individually and collectively (Lewis, Lange \& Gillis,2005). Transactive memory develops as a function of one person's beliefs about the knowledge possessed by another person and about the accessibility of that knowledge (Lewis, 2003). Recent studies have shown that a properly developed TMS facilitates knowledge retention which would necessarily improve team performance under various conditions (Faraj \& Sproull, 2000; Kanawattanachai \&Yoo, 2007; Lewis, 2004; Liang, Moreland \& Argote, 1995). Thus, it is hypothesized that;

$\mathrm{H} 2$ : There is a positive relationship between knowledge retention and team performance

Knowledge sharing is a team process where team members share task specific ideas, information, and suggestions with each other (Srivastava, Bartol \& Locke, 2006). Obviously, as per the literature, knowledge sharing is an important determinant of team performance.

Knowledge sharing in teams has been found to lead to superior team performance (Srivastava et al., 2006) where such superior team performance has been shown in different context such as new product development teams (Madhavan \& Grover, 1998), research and development teams (Bain, Mann, Atkins \& Dunning,2005) and software development teams (Faraj \& Sproull, 2000).Moreover, in line with those findings many studies have espoused the fact that knowledge sharing is critical for team performance
(Ancona \& Caldwell, 1992; Faraj \& Sproull, 2000; Hong, Doll, Nahm\& Li, 2004).Thus, it is hypothesized that;

H3: There is a positive relationship between knowledge sharing and team performance

KM concerns the formalization of and access to experience, knowledge, and expertise that create new capabilities, encourage innovation, enhance customer value and enable superior performance (Gloet \& Terziovski, 2004). Coleman (1999) defines KM as an umbrella term for a wide variety of interdependent and interlocking functions consisting of: knowledge creation; knowledge valuation and metrics; knowledge mapping and indexing; knowledge transport, storage and distribution; and knowledge sharing.

As per the prior discussions, Singh and Gupta (2014) have identified three main dimensions of knowledge management - knowledge creation, knowledge sharing and knowledge retention which are collectively termed as a team's knowledge management practices. The above mentioned hypotheses provide support from the literature for the relationships established between each dimension of knowledge management practices and team performance. Since those dimensions form team's knowledge management practices, they eventually support the positive relationship between team's knowledge management practices and team performance. Therefore, taking together all three dimensions which form knowledge management practices within team will lead to positive team performance Thus it is hypothesized that;

H4: There is a positive relationship between a team's knowledge management practices and team performance

\section{Iv Results and Discussion}

\section{A. Results}

With an adequate measurement model, the proposed hypotheses were tested with PLS. Having established the appropriateness of the measures, the next step is to provide evidence supporting the theoretical model (Chin, 2009 as cited in Wetzels et al., 2009).The model tests four hypotheses for the relationship between the factors affecting knowledge management practices (Knowledge creation, Knowledge retention and Knowledge sharing) and team performance.

The hypotheses from $\mathrm{H} 1$ to $\mathrm{H} 4$ were developed to examine the relationship between knowledge management practices and team performance. The results are given in Table 1.

Accordingly, the path coefficients for the above relationships are positive with the path regression coefficients of $0.175,0.250$ and 0.049 respectively. Further, for these path coefficients to be significant, the t-value should be greater than the significant critical values $(>1.96$, for significance at $95 \%$ level and $>2.65$, for significance at 99\% level). With that, H1 (T-stat: 1.2045) and H3 (T-stat: $0.316)$ are not significant at any significance level and only H2 (T-stat: 2.0091) is significant at 95\% significance level. 
Table 1: Hypotheses Testing $\left(\mathrm{H}_{1}-\mathrm{H}_{4}\right)$

\begin{tabular}{|l|l|l|l|}
\hline Hypotheses & P.C & T- stat & $\begin{array}{l}\text { P } \\
\text { Value }\end{array}$ \\
\hline $\begin{array}{l}\text { There is a relationship between knowledge } \\
\text { creation and team performance. }\left(\mathrm{H}_{1}\right)- \\
\text { Rejected }\end{array}$ & 0.1754 & 1.2045 & $\mathbf{0 . 2 2 8 5}$ \\
\hline $\begin{array}{l}\text { There is a relationship between knowledge } \\
\text { retention and team performance. }\left(\mathrm{H}_{2}\right)- \\
\text { Accepted }\end{array}$ & 0.2500 & 2.0091 & $\mathbf{0 . 0 4 4 7}$ \\
\hline $\begin{array}{l}\text { There is a relationship between knowledge } \\
\text { sharing and team performance. }\left(\mathrm{H}_{3}\right) \text {-Rejected }\end{array}$ & 0.0494 & 0.3166 & $\mathbf{0 . 7 5 1 6}$ \\
\hline $\begin{array}{l}\text { There is a relationship between a team's } \\
\text { knowledge management practices and team } \\
\text { performance. }\left(\mathrm{H}_{4}\right) \text {-Accepted }\end{array}$ & 0.408 & 5.6530 & $\mathbf{0 . 0 0 0}$ \\
\hline
\end{tabular}

Source: Survey data

Hence, it can be concluded that $\mathrm{H} 2$ is supported and $\mathrm{H} 1$, and $\mathrm{H} 3$, are not supported. Furthermore, the analysis shows that knowledge creation, knowledge sharing and knowledge retention at team level, jointly explain around eighteen percent $(18 \%)$ of the variance of team performance.

H4 of the study was to identify the relationship between knowledge management practices and team performance. Since this is a second order construct, to test the hypothesis the researcher used the parceling technique (Nasser \& Takahashi, 2003 as cited in Yang,Nay \& Hoyle, 2010). Accordingly, H4 was tested with the adoption of the parceling technique and the path coefficient represents 0.408. Along with a positive path coefficient, it gives a 5.653 (above 2.65) of $\mathrm{t}$ - stat which is significant at the $99 \%$ significance level. Hence, it can be concluded that $\mathrm{H} 4$ is supported.

\section{B. Discussion}

This analysis showed that a team's knowledge management practices influence team performance and the relationship is statistically significant. However, further analysis showed that knowledge retention, a dimension of knowledge management, has a positive effect on team performance, while knowledge creation and knowledge sharing, the remaining two dimensions do not.

Accordingly, the present study can be considered to confirm the aspects of the empirical findings (Faraj \& Sproull, 2000; Kanawattanachai \& Yoo, 2007; Lewis, 2004; Liang et al., 1995) which support the hypothesis developed in a way that shows a positive relationship between knowledge retention and team performance. However, considering all the dimensions collectively, a team's knowledge management practices had a positive and significant relationship with team performance where it can be supported contextually. In the Sri Lankan context, software and BPO companies are said to be engaging in knowledge management practices to a certain extent (Chan, 1998). However, given the contextual limitation, it is difficult to segregate those dimensions separately in a significant manner where people engage in all those activities under certain constraints.

\section{Iv. Summary and Conclusion}

The aim of this paper was to contribute to the existing body of knowledge by theorizing the effect of knowledge management practices on team performance. The findings of this study shed light on the presence of teams' knowledge management practices in achieving team performance. Accordingly, taking all the dimensions collectively, it can be concluded that a team's knowledge management practices positively and significantly predicts team performance. The findings further suggested that the effect of knowledge sharing, knowledge creation and knowledge retention on enhanced team performance is dependent on the duration for which the members exist within a team.

\section{A. Theoretical Implication}

The theoretical model was grounded in a knowledge based view theory. The findings of this study suggest that the knowledge based view theory can be a useful conceptual framework which will contribute to an understanding of the relationship between a team's knowledge management practices and its performance.

The knowledge-based view conceptualizes a core capability as a knowledge set that distinguishes one group from another which provides a competitive advantage (Leonard-Barton, 1992). The knowledge set may take the form of employee knowledge or skills, technical systems, managerial systems, or norms and values. The knowledgebased approach of a firm attempts to explore how organizations create, acquire, apply, protect, and transfer knowledge. Thus, Bierly and Chakrabarti (1996) believe that competitive advantages could be generated on the basis of the knowledge possessed by a firm and its ability to develop that knowledge.

Throughout the study, it was found that organized knowledge sharing sessions have to be cancelled or postponed due to other priorities of the team members as they may feel that knowledge sharing depletes the time and effort available for other work activities that can result in greater personal benefits and rewards by exceeding expectations on performance goals (Szulanski, 1996). Also, highly performance goal-oriented employees may not want to devote the time necessary engaging in exchanges with others who are attempting to understand and apply the shared knowledge to their work. As a result, they should be less likely to share knowledge.

Further, the duration in which the members are within the team also found to influence in effective engagement of knowledge sharing activities. In this study the teams have been found to be at the organization for a small duration (less than one year) most of the time. Teams which have been for more than one year as a team tend to show high cohesiveness among team members as well as highest score on knowledge sharing activities and vice versa. Moreover, knowledge creation is another critical factor in an organization's success and competitiveness. Nevertheless, 
with the status of information and documents where certain items of information and procedures are restricted to certain levels of employees (Ikshan \& Rowland, 2004), flow of knowledge across the organization is likely to prevented. Staff turnover is another problem for organizations which make it difficult to create the knowledge and apply at the organization effectively. With that it is apparent that these activities are crucial in achieving team performance, given the inherent difficulties.

\section{Acknowledgment}

This paper is based on my thesis being conducted under the MBA at Postgraduate Institute of Management, University of Sri Jayewrdenepura.

\section{References}

[1] Alavi, M., \& Leidner, D.E. (2001). Knowledge management and knowledge management systems: Conceptual foundations and research issues. MIS Quarterly, 25(1), 107-136.

[2] Al-Rawi, K. (2008). Cohesiveness within teamwork: The relationship to performance effectiveness - case study. Education, Business and Society, Contemporary Middle Eastern Issues, 1(2), 92 -106.

[3] Amy, E. (1999). Psychological safety and leaning behavior in work teams.Administrative Science Quarterly, 44, 350-83.

[4] Ancona, D. G.,\& Caldwell, D. F. (1992).Demography and design Predictors of new product team performance. Organizational Science, 3(3), 321-41.

[5] Argote, L., McEvily, B.,\& Reagans, R. (2003).Managing knowledge in organizations: An integrative framework and review of emerging themes. Management Science, 49(4), 571-582.

6] Atapattu, A.W.M.M., \& Jayakody, J.A.S.K. (2014). The interaction effect of organizational practices and employee values on knowledge management (KM) success. Journal of Knowledge Management, 18(2), $307-328$.

[7] Bain, P. G., Mann, L., Atkins, L.,\& Dunning, J. (2005). R\&D project leaders: Roles and responsibilities. Leadership,Management, and Innovation in R\&D Project Teams, 49-70.

[8] Barney, J. (1991). Firm resources and sustained competitive advantage. Journal of Management, 17(1), 99-120.

[9] Barney, J.B.,\& Wright, P.M. (1998).On becoming a strategic partner: The role of human resources in gaining competitive advantage. Human Resource Management, 37, 31-46.

[10] Bierly, P., \&Chakrabarti, A. (1996). Generic knowledge strategies in the U.S. pharmaceutical industry. Strategic Management Journal, 17, 123-136.

[11] Brown, J. S., \&Duguid, P. (1998). Organizing knowledge. California Management Review, 40, 90-111.

[12] Chan, D. (1998). Functional relations among constructs in the same content domain at different levels of analysis: A typology of composition models. Journal of Applied Psychology, 83(2), 234-246.

[13] Christina, A. (2003). Work team trust and effectiveness. Personnel Review, 32(5), 605-22.

[14] Cohen, S.G.,\& Bailey, D.E. (1997). What makes teams work: Group effectiveness research from the shop floor to the executive suite? Journal of Management, 23, 239-90.

[15] Coleman, D. (1999), "Groupware: collaboration and knowledge sharing", in Liebowitz, J.(ed), Knowledge Management Handbook, CRC Press, Boca Raton, FL

[16] Crossan, M., Lane, H. W., \& White, R. E. (1999).An organizational learning framework: From intuition to institution. Academy of Management Review, 24(3), 522-37.

[17] Cyr, S., \& Choo, C.W. (2010). The individual and social dynamics of knowledge sharing: An exploratory study. Journal of Documentation, 66(6), 824-846

[18] Davenport, T.H., \&Prusak, L. (1998).Working knowledge: How organizations manage what they know. Harvard Business Schoo Press, Boston, MA
[19] Davenport, T.H.,\& Grover, V. (2001). Special issue: Knowledge management. Journal of Management Information Systems, 18, 3-4.

[20] De Vries, R.E., Van den Hooff, B.,\& De Ridder, J.A. (2006). Explaining knowledge sharing: The role ofteam communication styles, job satisfaction and performance beliefs.Communication Research,33(2), 115-35.

[21] Devine, D.J.,\& Phillips, J.L. (2001). Do smarter teams do better? A meta-analysis of cognitive ability and team performance.Small Group Research, 32, 507-32

[22] Drucker, P. (1993). The Post Capitalist Society. Harper Business Press, New York, NY.

[23] Drucker, P. (1998). Managing in a Time of Great Change. New York: Dutton/Plume.

[24] Faraj, S. and Sproull, L. (2000). Coordinating expertise in software development teams.Management Science, 46(12), 1554-68.

[25] Ferran-Urdaneta, C. (1999).Teams or communities. Proceedings of the ACM SIGCPR Conference on Computer Personnel Research

[26] Gloet, M., \& Terziovski, M. (2004). Exploring the relationship between knowledge management practices and innovation performance. Journal of Manufacturing Technology Management, 15(5), 402-9.

[27] Gloet, M., \& Terziovski, M. (2004). Exploring the relationship between knowledge management practices and innovation performance. Journal of Manufacturing Technology Management, 15(5), 402-9.

[28] Grant R. M., (1996). Toward a knowledge-based theory of the firm. Strategic Management Journal, 17, 109-22

[29] Gupta, A.K., Smith, K.G.,\&Shalley, C.E. (2006). The interplay between exploration and exploitation. Academy of Management Journal, 49(4), 693-706.

[30] Hall, H. (2003). Borrowed theory: Applying exchange theories in information science research. Library and Information Science Research, 25(3), 287-306.

[31] Hansen, M.T., \&Oetinger, B.V. (2001). Introducing t-shaped managers: Knowledge management's next generation. Harvard Business Review, 79(3), 107-116.

[32] Hansen, M.T., Nohria, N., \& Tierney, T. (1999). What's your strategy for managing knowledge?. Harvard Business Review, 77(2), 106-116.

[33] Hollingshead, A.B. (2001). Cognitive interdependence and convergent expectations in transactive memory. Journal of Personality and Social Psychology, 81(6), 1080-1089.

[34] Hong, P., Doll, W. J., Nahm, A. Y. \& Li, X. (2004). Knowledge sharing in integrated product development. European Journal of Innovation Management, 7(2), 102-12.

[35] Hooff, V.B., \& Huysman, M. (2009). Managing knowledge sharing: Emergent and engineering approaches. Information and Management, 46(1), 1-8.

[36] Huang, C. (2009). Knowledge sharing and group cohesiveness on performance: An empirical studyof technology R\&D teams in Taiwan. Technovation, 29(11), 786-797

[37] Ikshan, S.O.S.S., \& Rowland, F. (2004). Knowledge Management in a public organization: A study on the relationship between organizational elements and the performance of knowledge transfer. Journal of Knowledge Management.8(2), 95-111.

[38] Jarvenpaa, S. L., \&Majchrzak, A. (2008). Knowledge collaboration among professionals protecting national security: Role of transactive memories in ego-centered knowledge networks. Organization Science, 19(2), 260-276

[39] Kanawattanachai, P., \& Yoo, Y. (2007). The impact of knowledge coordination on virtual team performance over time. MIS Quarterly, 31(4), 783-808.

[40] Kaplan, S., Schenkel, A., von Krogh, G., \& Weber, C. (2001). Knowledge-based theories of the firm in strategic management. A review and extension. Working paper, No. 4216-01, Massachusetts Institute of Technology, Boston.

[41] Kirkman, B.L.,\& Rosen, B. (1999). Beyond self-management: Antecedents and consequences of team empowerment.Academy of Management Journal, 42, 58-74.

[42] Kogut B., \&Zander, U. (1992). Knowledge of the firm, combinative capabilities and the replication of technology. Organization Science, 3(3), 383-98. 
[43] LeBreton, J.M., \&Senter, J.L. (2008).Answers to 20 questions about interrater reliability and interrater agreement.Organizational Research Methods, 11(4), 815-852.

[44] Leonard-Barton, D.(1992). Core capabilities and core rigidities: A paradox in managing new product development. Strategic Management Journal 13(8), 111-125.

[45] Lewis, K. (2003). Measuring transactive memory systems in the field: Scale development and validation. Journal of Applied Psychology, 88(4), 587-604

[46] Lewis, K., Lange, D.,\& Gillis, L. (2005).Transactive memory systems, learning, and learning transfer. Organization Science, 16(6), 581-598.

[47] Liang, D. W., Moreland, R., \& Argote, L. (1995). Group versus individual training and group performance: The mediating role of transactive memory.Personality and Social Psychology Bulletin, 21(4), 384-393

[48] Lopez, S.P., Peon, J.M.M.,\&Ordas, C.J.V. (2004). Managing knowledge: The link between culture and organizational learning. Journal of Knowledge Management, 8(6), 93-104.

[49] Lubit, R. (2001). Tacit knowledge and knowledge management: The keys to sustainable competitive advantage. Organizational Dynamics, 29(3), 164-178

[50] Madhavan, R., \& Grover, R. (1998). From embedded knowledge to embodied knowledge: New product development as knowledge management.Journal of Marketing, 62(4), 1-12.

[51] Marques, D.P., \& Simon F.J.G. (2006). The effect of knowledge management practices on firm performance. Journal of Knowledge Management,10(3), 143-156.

[52] Marsh, S.J.,\& Stock, G.N. (2006). Creating dynamic capability: The role of intertemporal integration, knowledge retention, and interpretation. Journal of Product Innovation Management, 23(5), 422-436.

[53] Nathan, B.R., Mohrman, A.M., \&Milliman, J. (1991). Interpersonal relations as a context for the effects of appraisal interviews on performance and satisfaction: A longitudinal study. Academy of Management Journal, 34, 352-69.

[54] Nonaka, I. (1991). The Knowledge-Creating Company.Harvard Business Review, 69(6), 96-104.

[55] Nonaka, I. (1994). A dynamic theory of organizational knowledge creation. Organization Science, 5, 14-37.

[56] Nonaka, I., \& Konno, N. (1998). The concept of "Ba": Building a foundation for knowledge creation. California, Management Review, 40, 40-54.

[57] Nonaka, I., \&Takeuchi, H. (1995). The knowledge-creating company: how Japanese companies create the dynamics of innovation. New York/Oxford: Oxford University Press.

[58] Oliver, G. (2008). Information culture: Exploration of differing values and attitudes toinformation in organizations.Journal of Documentation, 64(3), 363-85.

[59] Polanyi, M. (1966).The Tacit Dimension. New York: Anchor Day.

[60] Quinn, I. B. (1992). Intelligent Enterprise. New York: Free Press.

[61] Ramesh, B., \& Tiwana, A. (1999). Supporting collaborative process knowledge management in new product development teams. Decision Support System, 27,213-235.

[62] Singh, R.M., \& Gupta, M., (2014). Knowledge management in teams: Empirical integration and development of a scale. Journal of Knowledge Management, 18(4),777 - 794.

[63] Singh, S.K. (2008). Role of leadership in Knowledge Management. Journal of Knowledge Management, 12(4), 3-15.

[64] Skyrme, D.J., \&Amidon, D.M. (1998). New measures of success Journal of Business Strategy.19 (1).

[65] Spender, J.C. (1996). Organizational knowledge, learning and memory: Three concepts in search of a Theory. Journal of Organizational Change, 9(1), 63-78.

[66] Srivastava, A., Bartol, K.M.,\& Locke, E.A. (2006). Empowering leadership in management teams: Effects on knowledge sharing, efficacy, and performance.Academy of Management Journal, 49, 1239-51.

[67] Stewart, G.L., \&Barrick, M.R. (2000).Team structure and performance: Assessing the mediating role of intrateam process and the moderating role of task type. Academy of Management Journal, 43,135-48.

[68] Stewart, T.A. (1997). Intellectual Capital: The New Wealth of Organizations, Doubleday/Currency,New York, NY.

[69] Szulanski, G. (1996). Exploring internal stickiness: Impediments to the transfer of best practice within the firm. Strategic Management Journal, 17(2), 27-43.

[70] Teece, D.J. (2003). Knowledge and competence as strategic assets. Handbook on Knowledge Management, 1, 129-152.

[71] Toffler, A. (1990). Powershift: Knowledge,Wealth and Violence at the Edge of the 21st Century. Bantam Books, New York.

[72] Tsoukas, H. (1996). The firm as a distributed knowledge system: A constructionist approach. Strategic Management Journal, 17, 11-26

[73] Von Krogh G. (2002). The communal resource and information systems. Journal of Strategic Information Systems, 11(2), 85-107.

[74] Wareham, J., \&Gerrits, H. (1999). De-contextualisingcompetence: Can business be bundled and sold? European Management Journal, $16,39-49$.

[75] Wegner, D.M. (1995). A computer network model of human transactive memory. Social Cognition, 13(3), 319-339.

[76] Wenger, E.C., \& Snyder, W.M. (2000). Communities of practice: The organizational frontier. Harvard Business Review, 78(1), 139-145.

[77] Wetzels,M., Schroder,G.O., \&Oppen, C.V.(2009).Using PLS path modeling for assessing hierarchicalConstruct models: Guidelines and empiricallllustration. MIS Quartely, 33(1), 177-195.

[78] Wide'n-Wulff, G.,\&Ginman, M. (2004). Explaining knowledge sharing in organizations through the dimensions of social capital.Journal of Information Science, 30(5), 448-58.

[79] Woerkom, M.V., \& Croon, M. (2009). The relationships between team learning activities and team performance. Personnel Review, $38(5), 560-577$.

[80] Yang, C., Nay, S., Hoyle, R.H. (2010). Three approaches to using lengthy ordinal scales in structural equation models: Parceling, latent scoring, and shortening scales. ApplPsycholMeas, 34(2), 122142.doi: $10.1177 / 0146621609338592$

About Author (s):
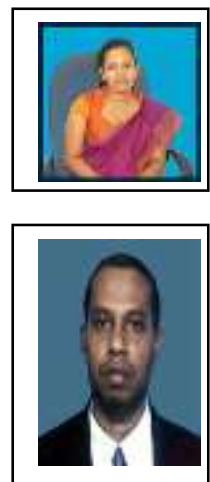

W.B.M.D.Basnayake Lecturer Department of Finance Faculty of Commerce and Management Studies University of Kelaniya Sri Lanka

J A S K Jayakody Associate professor in Management \& Organization Studies Head

Postgraduate Institute of Management

University of Sri Jayewardenapura Sri Lanka 